\title{
Development of Fungal Brown Spot and Spot Blotch on Cultivated Wild Rice in Minnesota
}

\author{
R. F. Nyvall, Professor, University of Minnesota, North Central Experiment Station, Grand Rapids 55744; and J. A. \\ Percich, Professor, Department of Plant Pathology, University of Minnesota, St. Paul 55108
}

\begin{abstract}
Nyvall, R. F., and Percich, J. A. 1999. Development of fungal brown spot and spot blotch on cultivated wild rice in Minnesota. Plant Dis. 83:936-938.

Symptoms of fungal brown spot of cultivated wild rice (Zizania palustris), caused by Bipolaris oryzae, initially occurred on the flag and lower aerial leaves of wild rice at the boot stage of development; whereas spot blotch symptoms, caused by $B$. sorokiniana, first occurred at the floating leaf stage of plant development on both the floating leaf and the first aerial leaves. The percentage of $B$. oryzae isolated from all lesions did not increase significantly until early grain formation. Lesion numbers then increased rapidly until plant maturity, when $B$. oryzae was isolated from 36.9 and $49.3 \%$ of all flag and bottom aerial leaf lesions, respectively. On both the flag and lower aerial leaves, the percentage of lesions yielding B. sorokiniana increased slowly until early grain formation, then increased rapidly until plant maturity, 17.6 and $14.1 \%$, respectively. Numerous spots on the floating and first aerial leaves, previously thought to be caused by Bipolaris spp. infections, were caused primarily by Nakataea sigmoidea, Colletotrichum spp., and Phoma spp. The number of conidia of B. oryzae produced per lesion under laboratory conditions was greatest from lesions on lower leaves from early-mid flowering until plant maturity. The number of conidia of $B$. sorokiniana from lesions on both upper and bottom leaves increased until early-mid flowering, then remained relatively constant until plant maturity except that the number of conidia from lesions on bottom leaves declined.
\end{abstract}

The Minnesota Cultivated Wild Rice Council estimates cultivated wild rice (Zizania palustris) is grown on approximately 6,882 ha in Minnesota and contributes over $\$ 41.6$ million to the state's economy (personal communication). Fungal diseases have been an important factor in the cultivation of wild rice since 1961, causing average annual losses of $\$ 2.5$ million (1). Depending upon disease severity, losses vary from slight to $75 \%$ $(1,6,7)$, with anecdotal evidence ascribing losses of $100 \%$ in fields where disease was especially severe. Most research efforts on disease have concentrated on fungal brown spot (FBS), formerly considered to be caused by two fungi, Bipolaris oryzae (teleomorph $=$ Cochliobolus miyabeanus) and $B$. sorokiniana (teleomorph $=C$. sativus). Based on symptomatology and etiology, FBS has been separated into two diseases. The name FBS was retained for

Corresponding author: Robert F. Nyvall E-mail: nyval001@tc.umn.edu

Published as paper 981220049 of the contribution series of the Minnesota Agricultural Experiment Station based on research conducted under Project 22-68. University of Minnesota Experiment Station 981220049 .

Accepted for publication 16 June 1999.

Publication no. D-1999-0728-01R

(C) 1999 The American Phytopathological Society the disease caused by $B$. oryzae, and spot blotch (SB) was applied to the disease caused by $B$. sorokiniana (8). Yield losses previously reported due to FBS were probably caused by both FBS and SB.

Kohls et al., reporting on growth-stagespecific yield loss experiments, indicated that FBS (B. oryzae) caused the greatest yield reductions when epidemics were initiated at the boot stage and successively diminished when initiated at heading, early grain elongation, and milk stages (7). Additionally, Percich et al. demonstrated that the highest rates of infection by $B$. oryzae occurred at temperatures of 25 and $30^{\circ} \mathrm{C}$ and generally increased with continuous wet periods of $16,18,24$, and $28 \mathrm{~h}$ (10). These disease conditions do not always occur during the growing season or coincide with initiation of disease as demonstrated by Kohls and Percich (6). However, despite disease conditions, both FBS and SB are consistently observed at plant maturity, but at various levels of incidence and severity.

Currently, the fungicide propiconazole (Tilt) is used to control FBS on cultivated wild rice in Minnesota and is normally applied on a calendar schedule beginning in early July, or when environmental conditions are thought to be favorable for disease $(6,7,9)$, and again 14 days later. The first fungicide application is when plants are in a wide range of growth stages from early aerial leaf to boot. However, propiconazole often results in erratic dis- ease control. This has led to uncertainty as to the proper time of fungicide application and efficacy of labeled rates. To facilitate effective and timely fungicide application, the objective of this research was to determine the stages of development where FBS and SB occurred, to facilitate effective and timely fungicide application. Additionally, an understanding of the growth stages at which these diseases occur would help implement alternative disease control measures.

\section{MATERIALS AND METHODS}

Bipolaris spp. were isolated by placing pieces of leaf with lesions in running tap water for $1 \mathrm{~h}$ to remove dust and other extraneous material. Samples were dipped for $1 \mathrm{~min}$ into a $1: 1$ solution of $1 \%$ $\mathrm{NaOHCl}$ and $75 \% \mathrm{ETOH}$, rinsed in sterile distilled water, and placed onto moistened autoclaved filter paper (Whatman no. 1) in 9-cm-diameter plastic petri dishes. Samples were incubated utilizing available laboratory light at 22 to $26^{\circ} \mathrm{C}$ and examined after 10 to 14 days for growth of $\mathrm{Bi}$ polaris spp. using a stereo microscope $(\times 30$ to 60$)$ with a fiberoptic illuminator.

Following isolation, Bipolaris spp. were identified in situ by their conidial characteristics. B. oryzae conidia are light to golden brown, fusoid, obclavate to almost cylindrical, generally curved with 6 to 14 septa, and 14 to $22 \times 63$ to $153 \mu \mathrm{m}$ in size. $B$. sorokiniana conidia are olive to dark brown, ovate to oblong with tapered ends, with 3 to 10 septa, and 15 to $20 \times 60$ to 120 $\mu \mathrm{m}$.

Sampling of leaves was done weekly throughout the 1994 to 1997 growing seasons at the following stages of plant development based on criteria by Grava and Raisanen (4): floating leaf, aerial leaf, boot, early-mid flowering, early grain formation, and maturity. At the floating leaf stage, plants have formed one or two aerial leaves and the floating leaf. By the aerial leaf stage, three aerial leaves have formed, and the floating leaf has mostly disintegrated. At the boot stage, the flag or fourth aerial leaf has formed, with most plants only forming four aerial leaves. At maturity, the bottom aerial leaf has begun to senesce and become moribund on some plants.

Four cultivated wild rice fields, each representative of a major growing area in Minnesota, were selected. In each field, five sampling sites, each consisting of a 
population of plants within a 2-m-diameter area, were established $20 \mathrm{~m}$ apart in a circular pattern beginning $25 \mathrm{~m}$ from the field entrance. Each week, beginning at the floating leaf stage, leaf tissue with 20 lesions was randomly selected from the bottom and topmost fully developed leaves of approximately 10 plants at each site (except at the floating leaf stage) for a total of 100 lesions per top and bottom leaf per field. Thus, at the floating leaf stage, the first aerial and floating leaves were sampled; at the aerial leaf stage, the third and bottom aerial leaves were sampled; and at all other stages, the flag leaf and the bottom aerial leaves were sampled. As plants matured, the bottom senescing leaves continued to be sampled to determine if fungi colonized moribund tissue, thus providing a possible overwintering site. The data from the four fields were bulked at each weekly sampling time for a total of 400 lesions each from the bottom and top leaves.

Plant development stages for wild rice plants within a field do not occur uniformly. Therefore, each stage of development in Table 1, except for the floating and aerial leaf stages, is the combined data for 2 weeks.

Disease was measured on the top and bottom leaves of five plants per site for a total of 25 plants per field using a modified Septoria disease assessment key (5). Ratings of $1 \mathrm{~F}$ to 50 were utilized, corresponding to percentage of diseased leaf area $(1 \mathrm{~F}=0.5$ or flecks and $50=50+\%$ of leaf area diseased, respectively). The results from the four fields were combined for each sampling period and then combined for 1994 to 1997 . Therefore, each disease rating is the result of 400 observations. The lesions of both diseases were included in the disease rating. The typical leaf symptom caused by $B$. oryzae was a cigar-shaped lesion, $1.7 \mathrm{~cm}$ in length, with a straw to light to dark brown colored interior surrounded by a yellow halo, probably caused by the nonspecific toxin ophiobolin. Leaf symptoms caused by $B$. sorokiniana were irregular-shaped, $0.5 \times 1.5 \mathrm{~cm}$ or larger, and dark brown in color. The chlorotic halo was not observed. However, immature and mature lesions often tend to be similar in appearance.

Conidia produced on lesions in the laboratory were counted to determine if their numbers changed at different stages of plant development, thus representing changes in secondary inoculum throughout the growing season. Conidial counts were done in two ways. If conidia on a lesion were too numerous to accurately count, the lesion was divided into four sections, all of the conidia in a section were counted $(\times 30)$, and this number was multiplied by four to approximate the number of conidia produced within the lesion. All conidia were counted in lesions where fewer conidia were produced. Conidia were counted for 1996 to 1997 only.
Data were analyzed by analysis of variance with mean separations by Duncan's $t$ test $(P=0.05)$ using Statview Version 4.02 (Abacus Concepts Inc., Berkeley, CA).

\section{RESULTS}

FBS (B. oryzae) symptoms were first observed on cultivated wild rice at the boot stage, when it was isolated from 6.5 and $6.2 \%$ of total lesions on the flag leaf and bottom aerial leaf, respectively (Table 1). The percentage of $B$. oryzae isolates obtained from total lesions did not increase significantly until the early grain formation stage, when the fungus was isolated from 20.9 and $21.3 \%$ of lesions on the flag and bottom aerial leaf, respectively. The percentage of $B$. oryzae isolated from lesions continued to increase until maturity, when it was isolated from 36.9 and $49.3 \%$ of all flag and bottom aerial leaf lesions, respectively. At maturity, the bottom leaves of many plants had begun to senesce and turn brown.

Although $B$. oryzae was not isolated at either the floating or the aerial leaf stage, numerous spots could be detected on floating and aerial leaves of some plants. Most spots on the floating leaf were caused by Nakataea sigmoidea (teleomorph =
Magnaporthe salvinii, synanamorph = Sclerotium oryzae), causal fungus of the leaf sheath and stem rot disease of wild and common rice (Oryzae sativa). However, many spots on the aerial leaves were also likely caused by other fungi, such as Colletotrichum spp. and Phoma spp. (unpublished).

The number of $B$. oryzae conidia was greatest in lesions on the bottom leaves, beginning at early-mid flowering and increasing until maturity (Table 2).

B. sorokiniana was first detected at a low incidence from lesions on both the floating and the first aerial leaves at the floating leaf stage (Table 1). The percentage of lesions yielding $B$. sorokiniana continued to increase until maturity, when it was recovered from 17.6 and $14.1 \%$ of lesions on the flag and bottom aerial leaves, respectively (Table 1 ).

The number of $B$. sorokiniana conidia per lesion in the laboratory test increased until the early-mid flowering stage, then remained constant until maturity with the exception of the number of conidia in lesions from the bottom aerial leaf (Table 2).

\section{DISCUSSION}

Previously, B. oryzae was erroneously thought to infect cultivated wild rice in the

Table 1. Percentage of leaf lesions yielding Bipolaris oryzae and B. sorokiniana on the leaves of cultivated wild rice at different stages of plant development in Minnesota in 1994 to 1997

\begin{tabular}{llccc}
\hline $\begin{array}{l}\text { Stage of plant } \\
\text { development }\end{array}$ & Source of lesions & $\begin{array}{c}\text { B. oryzae } \\
(\%)\end{array}$ & $\begin{array}{c}\text { B. sorokiniana } \\
(\%)\end{array}$ & Disease rating \\
\hline Floating leaf & First aerial leaf & $0.0 \mathrm{a}$ & $0.4 \mathrm{a}$ & $0.5 \mathrm{a}$ \\
& Floating leaf & $0.0 \mathrm{a}$ & $0.1 \mathrm{a}$ & $0.5 \mathrm{a}$ \\
Aerial leaf & Third aerial leaf & $0.0 \mathrm{a}$ & $4.6 \mathrm{a}$ & $1.9 \mathrm{a}$ \\
& Bottom aerial leaf & $0.0 \mathrm{a}$ & $1.1 \mathrm{a}$ & $3.7 \mathrm{a}$ \\
Boot & Flag leaf & $6.5 \mathrm{a}$ & $2.4 \mathrm{a}$ & $1.7 \mathrm{a}$ \\
& Bottom aerial leaf & $6.2 \mathrm{a}$ & $3.2 \mathrm{a}$ & $25.0 \mathrm{~b}$ \\
Early-mid & Flag leaf & $5.7 \mathrm{a}$ & $1.1 \mathrm{a}$ & $5.4 \mathrm{a}$ \\
flowering & Bottom aerial leaf & $4.5 \mathrm{a}$ & $1.7 \mathrm{a}$ & $30.3 \mathrm{~b}$ \\
Early grain & Flag leaf & $20.9 \mathrm{~b}$ & $6.8 \mathrm{a}$ & $15.1 \mathrm{a}$ \\
formation & Bottom aerial leaf & $21.3 \mathrm{~b}$ & $5.8 \mathrm{a}$ & $51.7 \mathrm{c}$ \\
Maturity & Flag leaf & $36.9 \mathrm{c}$ & $17.6 \mathrm{~b}$ & $25.4 \mathrm{~b}$ \\
& Bottom aerial leaf & $49.3 \mathrm{~d}$ & $14.1 \mathrm{~b}$ & $75.3 \mathrm{~d}$ \\
\hline
\end{tabular}

${ }^{\mathrm{y}}$ Ratings followed by the same letter were not significantly different $(P=0.05)$.

${ }^{\mathrm{z}}$ Statistics on disease ratings were performed separately from percent lesions yielding $B$. oryzae and $B$. sorokiniana. Ratings followed by the same letter are not significantly different $(P=0.05)$. Disease rating was caused by both pathogens.

Table 2. Average number of conidia of Bipolaris oryzae and B. sorokiniana produced in lesions on top aerial leaf compared with bottom leaf of wild rice plants at different stages of plant development

\begin{tabular}{llcc}
\hline \multirow{2}{*}{$\begin{array}{l}\text { Stage of plant } \\
\text { development }\end{array}$} & Source of lesions & \multicolumn{2}{c}{ Average no. of conidia per lesion } \\
\cline { 3 - 4 } Floating leaf & First aerial leaf & B. oryzae & B. sorokiniana \\
\hline \multirow{2}{*}{ Aerial leaf } & Floating leaf & $0 \mathrm{a}$ & $21 \mathrm{a}$ \\
& Top (3rd) aerial leaf & $0 \mathrm{a}$ & $7 \mathrm{a}$ \\
Boot & Bottom aerial leaf & $0 \mathrm{a}$ & $47 \mathrm{ab}$ \\
& Flag (4th) aerial leaf & $0 \mathrm{a}$ & $35 \mathrm{ab}$ \\
Early-mid & Bottom aerial leaf & $94 \mathrm{~b}$ & $75 \mathrm{~b}$ \\
flowering & Flag (4th) aerial leaf & $53 \mathrm{~b}$ & $57 \mathrm{~b}$ \\
Early grain & Bottom aerial leaf & $58 \mathrm{~b}$ & $232 \mathrm{c}$ \\
formation & Flag (4th) aerial leaf & $94 \mathrm{~b}$ & $221 \mathrm{c}$ \\
Maturity & Bottom aerial leaf & $32 \mathrm{~b}$ & $225 \mathrm{c}$ \\
& Flag (4th) aerial leaf & $112 \mathrm{~b}$ & $213 \mathrm{c}$ \\
- & Bottom aerial leaf & $241 \mathrm{c}$ & $210 \mathrm{c}$ \\
\end{tabular}

${ }^{\mathrm{z}}$ Ratings followed by the same letter were not significantly different $(P=0.05)$. 
field at the floating and aerial leaf stages of plant development (1). These early infections were thought to contribute to the more severe disease symptoms that occurred later in the growing season. The early presence of FBS lesions was then assumed to be a forewarning of severe disease later in the growing season and formed the basis for fungicide recommendations. However, only a small percentage of the lesions on the floating and first aerial leaves were caused by $B$. sorokiniana and none were caused by $B$. oryzae during a 4-year period. During warm and moist conditions in the greenhouse and growth chamber, $B$. oryzae has been shown to infect the floating and first aerial leaves (10). However, during our tests, the conditions necessary for infection were apparently not present in the field during these stages of plant development.

We found that FBS symptoms were not present until the boot stage. Thereafter, disease severity, as indicated by the number of lesions from which B. oryzae was isolated, steadily increased until maturity. The bottom aerial leaves had more lesions and produced more conidia per lesion than the flag leaves. While many lower leaves were senescent at this time and contributed little or nothing to grain development, these conidia may represent a potential source of secondary inoculum that could infect flag leaves, stems, and grain.

Several interrelated reasons may suggest why FBS symptoms were not present until the boot stage. First, the microclimate was apparently not favorable for infection and subsequent disease development by $B$. oryzae until warmer weather and longer dew periods later in the season produced conditions similar to those in the growth chamber described by Percich et al. (10).

A second reason is that wild rice plants are not susceptible to infection by $B$. oryzae until the boot stage. This may relate to an increase in the quantity of inoculum or to plant nutrient status. We theorize that primary inoculum is produced at a few overwintering sites during the early part of the growing season and eventually becomes abundant enough to cause infections coinciding with boot stage (unpublished). $B$. oryzae is thought to be a good pathogen of wild rice but a poor saprophyte on moribund tissue (unpublished). The fungus is also a minor pathogen of other potential grass hosts growing on dikes (unpublished). Therefore, overwintering by $B$. oryzae probably occurs on residue that remains relatively dry until the next growing season. However, low initial infection at the boot stage may be adequate, given proper environmental conditions, to produce abundant secondary inoculum that can cause severe disease later in the season.

A third possible reason is that draining water from fields preparatory to harvest when plants are in the boot stage may place plants under physiological stress and, combined with poor nutrient availability in some cases, cause plants to be more susceptible to infection. Similarly, draining of water from fields leads to nitrogen deficiency and increased brown spot in common rice (2). Dodd proposes a related theory that maize, and presumably other plants, are predisposed to disease because of a carbohydrate shortage in the plant (3). This shortage is caused by a combination of the reduction in leaf photosynthesis and intraplant competition for carbohydrates by developing kernels.

We conclude that FBS occurs on cultivated wild rice later in the growing season than previously thought. Symptoms of FBS do not occur until the boot stage, whereas symptoms of SB occurred at a low incidence throughout the growing season, becoming more abundant from early grain formation until maturity. The numerous leaf spots frequently found on diseased plants before the boot stage are caused by other fungi, particularly $N$. sigmoidea, Phoma sp., and Colletotrichum sp. There- fore, the application of propiconazole too early in the growing season results in ineffectual control of FBS, because the disease is either not present or at a low incidence. However, the second application, approximately 14 days later, occurs when the incidence of FBS is increasing. We suggest one application at early grain formation for effective control of FBS.

\section{ACKNOWLEDGMENTS}

We thank Laura Wagner for technical assistance and Ann Arendt and Leslie Johnson for help in the preparation of this manuscript. This study was supported in part by funding from the Minnesota Cultivated Wild Rice Council and the Agricultural Utilization Research Institute.

\section{LITERATURE CITED}

1. Bean, G. A., and Schwartz, R. 1961. A severe epidemic of Helminthosporium brown spot disease on cultivated wild rice in Minnesota. Plant Dis. Rep. 45:901.

2. Chattopadhyay, S. B., and Dicson, J. G. 1950. Relation of nitrogen to disease development in rice seedlings infected with Helminthosporium oryzae. Phytopathology 50:434-438.

3. Dodd, J. L. 1980. Grain sink size and predisposition of Zea mays to stalk rot. Phytopathology 70:534-535.

4. Grava, J., and Raisanen, K. A. 1978. Growth and nutrient accumulation and distribution in wild rice. Crop Sci. 23:956-960.

5. James, C. 1971. A manual of assessment keys for plant diseases. Can. Dep. Agric. Publ. No. 1458. Key No. 1.6.1.

6. Kohls, C. L., and Percich, J. A. 1984. Epidemiology and yield losses associated with fungal brown spot of wild rice. (Abstr.) Phytopathology 74:809.

7. Kohls, C. L., Percich, J. A., and Huot, C. M. 1987. Wild rice yield losses associated with growth-stage-specific fungal brown spot epidemics. Plant Dis. 71:419-422.

8. Nyvall, R. F., Percich, J. A., and Brantner, J. R. 1994. Fungal brown spot of cultivated wild rice is two different diseases. (Abstr.) Phytopathology $84: 1102$.

9. Percich, J. A. 1989. Comparison of propiconazole rates for control of fungal brown spot of wild rice. Plant Dis. 73:588-589.

10. Percich, J. A., Nyvall, R. F., Malvick, D. K., and Kohls, C. L. 1997. Interaction of temperature and moisture on infection of wild rice by Bipolaris oryzae in the growth chamber. Plant Dis. 81:1193-1195. 